\title{
CÁC VĂN HÓA BIỂN TIỀN SỬ VIÊTT NAM - GIÁ TRỊ LỊCH SỬ VĂN HÓA NỔI BẬT
}

\author{
Nguyễn Khắc Sử ${ }^{a^{*}}$ \\ ${ }^{a}$ Viện Khảo cổ học Việt Nam, Hà Nội, Việt Nam \\ *Tác giả liên hệ: Email: khacsukc@gmail.com \\ Lịch sử bài báo \\ Nhận ngày 12 tháng 01 năm 2020
}

Chỉnh sửa ngày 05 tháng 02 năm 2020 | Chấp nhận đăng ngày 19 tháng 02 năm 2020

\section{Tóm tắt}

Văn hoá biển tiền sủ Việt Nam là văn hoá của các cộng đồng cu dân cổ xưa ở giai đoạn chưa có chũ viết, chura có giai cấp, chưa có nhà nước, sống trong môi truờng biển, khai thác các nguồn lợi biển, và có quan hệ rộng rãi với xung quanh, tạo dựng nền văn hoá mang đậm màu sắc biển (Nguyễn, 1997, tr. 16-28). Lịch sủ Trái đất đã trải qua ít nhất 20 chu kỳ băng hà gian băng và là ngần ấy thời kỳ biển tiến và biển lùi, đó là chưa kể đến nhũng dao động nhỏ giữa các giai đoạn hoặc do tân kiến tạo làm cho biên độ dao động mức nuớc biển ở tùng khu vưc cũng khác nhau. Dao động mưc nước ở Biển Đông trong quá khư không chỉ quyết định về không gian sinh tồn, mà còn có quá trình hình thành các nền văn hóa biển tiền sử Việt Nam. Bài viết này sẽ trình bày và luận bàn chính về các vấn đề: Lịch sủ chiếm cu vùng biền và hải đảo; Quá trình hình thành các nền văn hóa biển tiền sử Việt Nam; và Giá trị lịch sủ văn hóa và vị trí của văn hóa biển trong bối cảnh rộng hơn.

Từ khóa: Holocene; Pleisocene; Tiền sử Việt Nam; Văn hóa biển thời tiền sử; Văn hóa biển Việt Nam.

DOI: http://dx.doi.org/10.37569/DalatUniversity.10.2.639(2020)

Loại bài báo: Bài báo nghiên cứu gốc có bình duyệt

Bản quyền (C) 2020 (Các) Tác giả.

Cấp phép: Bài báo này được cấp phép theo CC BY-NC 4.0 


\title{
VIETNAMESE PREHISTORIC MARINE CULTURES - OUTSTANDING HISTORICAL AND CULTURAL VALUES
}

\author{
Nguyen Khac Su${ }^{a^{*}}$ \\ ${ }^{a}$ The Institute of Archaeology, Hanoi, Vietnam \\ ${ }^{*}$ Corresponding author: Email: khacsukc@gmail.com \\ Article history \\ Received: January $12^{\text {th }}, 2020$ \\ Received in revised form: February $5^{\text {th }}, 2020 \mid$ Accepted: February $19^{\text {th }}, 2020$
}

\begin{abstract}
Vietnamese prehistoric marine culture is the culture of ancient communities who had no written languages, social classes, or states. The inhabitants lived in coastal environments, exploited marine resources, had relations with broad surrounding areas, and created a bold marine culture (Nguyen, 1997, pp. 16-28). Earth's history has gone through at least 20 glacial and interglacial cycles in which the sea advanced and receded, not to mention the small fluctuations between stages, or those due to tectonic activity that made sea-level changes vary in each region. Fluctuations in past water levels in the East Sea determined not only the space for survival, but also the process of forming prehistoric Vietnamese marine cultures. This article discusses the following issues: The history of exploiting seas and islands, the process of developing ancient Vietnamese oceanic cultures, cultural-historical values, and the position of maritime culture in the broader context.
\end{abstract}

Keywords: Holocene; Marine prehistoric culture; Pleistocene; Prehistoric Vietnam; Vietnamese marine culture.

DOI: http://dx.doi.org/10.37569/DalatUniversity.10.2.639(2020)

Article type: (peer-reviewed) Full-length research article

Copyright (C) 2020 The author(s).

Licensing: This article is licensed under a CC BY-NC 4.0 


\section{MỞ ĐẦU}

Việt Nam ở Đông Nam Á có ưu thế rõ rệt, là cầu nối liền Đông Nam Á lục địa với Đông Nam Á hải đảo. Đường bờ biển của Việt Nam dài $3,260 \mathrm{~km}$, cứ $100 \mathrm{~km}^{2}$ đất liền thì có $1 \mathrm{~km}$ đường biển (Thế giới trung bình $600 \mathrm{~km}^{2}$ đất liền có $1 \mathrm{~km}$ bờ biển). Trên hải phận của Việt Nam có hàng nghìn hòn đảo và quần đảo nối liền với đất liền thông qua thềm lục địa rộng lớn.

Biển Đông có diện tích 3,537,000km², trong đó biển Việt Nam chiếm gần 1/3 diện tích. Điểm nổi bật của Biển Đông là loại biển kín được lục địa châu Á và các quần đảo Philippines và Indonesia bao bọc. Biển Đông thông ra Thái Bình Dương và các biển liền kề bằng một số eo hẹp như: Eo biển Đài Loan (Trung Quốc), eo biển Luzon (Philippines), eo biển Malaysia, và eo biển Palawan (Philippines). Tính chất biển kín đã ảnh hưởng đến đặc điểm các dòng biển, thủy triều, giới sinh vật, cũng như hoạt động sống của cư dân biển từ thời tiền sử đến lịch sử.

Có thể nói, Biển Đông có một vị thế hết sức quan trọng trên bình đồ châu Á với ba tiêu chí: Vị thế tự nhiên, địa kinh tế, và địa chính trị. Nơi đây sở hữu nguồn tài nguyên lớn cho các quốc gia xung quanh trong tiền sử cũng như ngày nay. Đây là con đường hàng hải huyết mạch cho nhiều nước trên thế giới, là nơi giao thoa của nhiều nền văn hóa, văn minh nhân loại, và là nơi có vị thế địa quân sự mang tầm quốc tế (Lê \& Trần, 2011, tr. 59). Hiện nay, ở Việt Nam có 26 tỉnh/thành phố ven biển, chiếm trên $42 \%$ diện tích và hơn 45\% dân số của cả nước, với khoảng 15.5 triệu người sống ở ven bờ và khoảng 16 vạn người sống trên các đảo. Đây là lực lượng trực tiếp bảo vệ và khai thác bền vững tài nguyên vùng biển chủ quyền của đất nước, trong đó có tài nguyên văn hóa biển.

Vấn đề đặt ra là lịch sử chiếm cư vùng biển và hải đảo của cư dân tiền sử Việt Nam có từ bao giờ? Quá trình hình thành các nền văn hóa biển tiền sử Việt Nam ra sao? Giá trị lịch sử - văn hóa và vị trí của chúng trong bối cảnh rộng hơn như thế nào? Đó là những nội dung cơ bản sẽ được trình bày trong bài báo này.

\section{CÁC VĂN HÓA BIỂN TRONG TIỀN SỬ VIẸTT NAM}

\subsection{Giai đoạn 40,000 năm $B P$ đến 20,000 năm $B P$}

Đợt biển tiến 40,000 năm BP (Before Present) với nước biển dâng cao làm ngập chìm đới bờ hiện tại và lấn sâu vào lục địa, phủ kín phần lớn đồng bằng sông Hồng hiện nay. Dấu vết đợt biển tiến này còn thấy trên ngấn nước ở hòn Hang Dinh, ở độ cao 7.05 - 7.85m, có niên đại C14 từ 32,960 4689 năm BP đến trên 40,000 năm BP (Nguyễn, N., 2005 , tr. 66). Vùng đồng bằng Bắc Bộ lúc này đã tìm thấy di cốt người Khôn ngoan (Homo sapiens) ở hang Thánh Hóa, Hải Dương, một dãy núi đá vôi ở vùng Kim Môn, Hải Dương (Nguyễn \& Nguyễn, 2018, tr. 33-37). Rất tiếc là cho đến nay vẫn chưa tìm thấy công cụ lao động và hóa thạch người giai đoạn 40,000 năm BP.

Trong giai đoạn này, nằm sâu trong lục địa ở Bắc Việt Nam xuất hiện kỹ nghệ Ngườm (tỉnh Thái Nguyên), niên đại của văn hóa này từ 40,000 năm BP đến 23,000 năm 
BP, và văn hóa Sơn Vi (Phú Thọ) có niên đại từ 30,000 năm BP năm đến 11,000 năm BP (Hà, Nguyễn, \& Trình, 1998, tr. 152). Thành phần bào tử phấn hoa cho thấy, giai đoạn này là của các loài ưa nóng như Polypodiaceae, Palmae, Quercus..., một số ít loài ưa lạnh như Juglams, Pinus..., đặc trưng cho thảm thực vật rừng cây lá rộng là chính, ngoài ra còn có một số loài lá kim và đều là các cánh rừng thường xanh quanh năm, thuộc khí hậu nhiệt đới gió mùa, có một mùa hè nóng ẩm, mưa nhiều, và một mùa đông khô lạnh, ít mưa (Nguyễn, N., 2005, tr. 67).

Nhìn chung, ở khu vực Việt Nam và Đông Nam Á giai đoạn 40,000 năm BP đến 20,000 năm $B P$ có biên độ dao động nhiệt độ đáng kể. Vào khoảng 30,000 năm $B P$, toàn bộ lục địa Đông Nam Á trở nên khô lạnh. Tương ứng với thời kỳ này là sự xuất hiện các kỹ nghệ mảnh tước nhỏ và tu chỉnh kiểu Ngườm. Sau đó, khí hậu nóng dần lên, có thể chia ra hai thời kỳ, một thời kỳ nóng nhưng tương đối khô và một thời kỳ nóng ẩm. Giai đoạn nóng dần lên này được đánh dấu bằng sự xuất hiện các kỹ nghệ cuội ghè thuộc phạm trù văn hóa Sơn Vi và văn hóa Hoà Bình (Ha, 1985, tr. 81).

\subsection{Giai đoạn 20,000 năm BP đến 8,000 năm BP}

Sau 20,000 năm BP, biển còn ở xa, toàn bộ vịnh Bắc Bộ là đồng bằng trước núi rộng lớn. Một bộ phận núi đá vôi, hang động, thung lũng, và sông suối hầu như vẫn được bảo tồn ở đáy vịnh Bắc Bộ. Vào khoảng 18,000 năm $\mathrm{BP}$, nước biển bắt đầu dâng, phải đến 10,000 năm $\mathrm{BP}$ mực nước biển mới đạt đường đẳng sâu $-30 \mathrm{~m}$, và đến 7,000 năm $\mathrm{BP}$ vẫn chưa tới đường bờ hiện nay. Khí hậu giai đoạn này là nhiệt đới gió mùa rõ rệt, từ nóng khô đến nóng ẩm, tính chất của các mùa trong năm thể hiện rõ ràng, được minh chứng bởi phấn hoa của các loài ưa nóng (rừng cây lá rộng, thường xanh) phát triển rộng, xen lẫn thực vật lá nhọn ưa khô, lạnh (Nguyễn, N., 2005, tr. 68).

Giai đoạn biển thoái Pleistocene, đồng bằng ven biển lộ ra, một số cư dân sống trên vùng ven biển bấy giờ vẫn còn là lục địa. Vết tích văn hóa của cư dân tiền sử lúc này còn bảo lưu trong một số di tích ven biển ở vịnh Hạ Long hiện nay như: Di tích hang Áng Mả (Cát Bà, Hải Phòng) niên đại 25,510 \pm 220 năm BP; Mái đá Ông Bảy (Cát Bà) niên đại 16,630 \pm 120 năm BP; Hang Soi Nhụ (Quảng Ninh) niên đại 14,460 \pm 60 năm BP và $15,560 \pm 180$ năm $\mathrm{BP}$. Họ là những người sử dụng nguyên liệu đá cuội để chế tác công cụ kiểu Hòa Bình như rìu hình bầu dục, rìu ngắn, nạo hình đĩa, rìu mài lưỡi... Họ săn bắt các loài động vật trên cạn, thu lượm các loài nhuyễn thể nước ngọt, và sống trong môi trường lục địa.

Phần lớn cư dân văn hoá Hoà Bình (17,000 năm $\mathrm{BP}$ đến 7,000 năm $\mathrm{BP})$ và cư dân văn hóa Bắc Sơn $(11,000$ năm $\mathrm{BP}$ đến 7,000 năm $\mathrm{BP})$ nằm sâu trong lục địa và sống xa biển. Nhưng ở một số di tích, con người cổ đã biết đến tặng vật của biển, đó là đồ trang sức từ vỏ ốc biển (cypraea). Chúng được mài thủng lỗ và xâu chuỗi làm đồ trang sức hoặc làm đồ tùy táng chôn theo người chết. Những tặng vật của biển ấy có thể là sản phẩm trao đổi với cư dân sống gần biển. Nhìn chung, trước 20,000 năm BP, dấu tích khai thác biển còn mờ nhạt và nhỏ lẻ. Dường như truyền thống ở hang động, chế tác công cụ cuội, và khai thác nhuyễn thể nước ngọt trong các sông suối vẫn níu kéo cư dân tiền sử vùng này, 
đã làm chậm lại sự tiếp cận, giao thoa, và hòa nhập với môi trường biển (Nguyễn, 1995, tr. 10).

Trong số những cư dân khai thác biển, sớm nhất hiện biết là cư dân cổ ở Tràng An (Ninh Bình), nơi giờ đây đã trở thành lục địa. Trước 9,000 năm $\mathrm{BP}$, biển chưa đến vùng Tràng An, nhưng cư dân ở đây đã biết đến đồ trang sức bằng vỏ nhuyễn thể biển. Các vỏ ốc loài Netrita undata có thân nhỏ, vỏ dày, màu trắng sáng, được mài thủng trôn tạo lỗ xâu dây đeo kiểu hạt chuỗi tìm thấy ở hang Bói (Hình 1). Nhưng vào khoảng 10,620 năm $\mathrm{BP}$, người cổ ở đây lại chuộng đồ trang sức từ vỏ các loài ốc biển Neritina of pulligera và loài Cypraea sp., vốn có dáng miệng đẹp, được mài thủng lưng, đôi khi nhuộm thổ hoàng (màu đỏ), được dùng làm hạt chuỗi trang sức tìm thấy ở các địa điểm Thung Bình, hang Trống, và một số hang động khác (Hình 1).

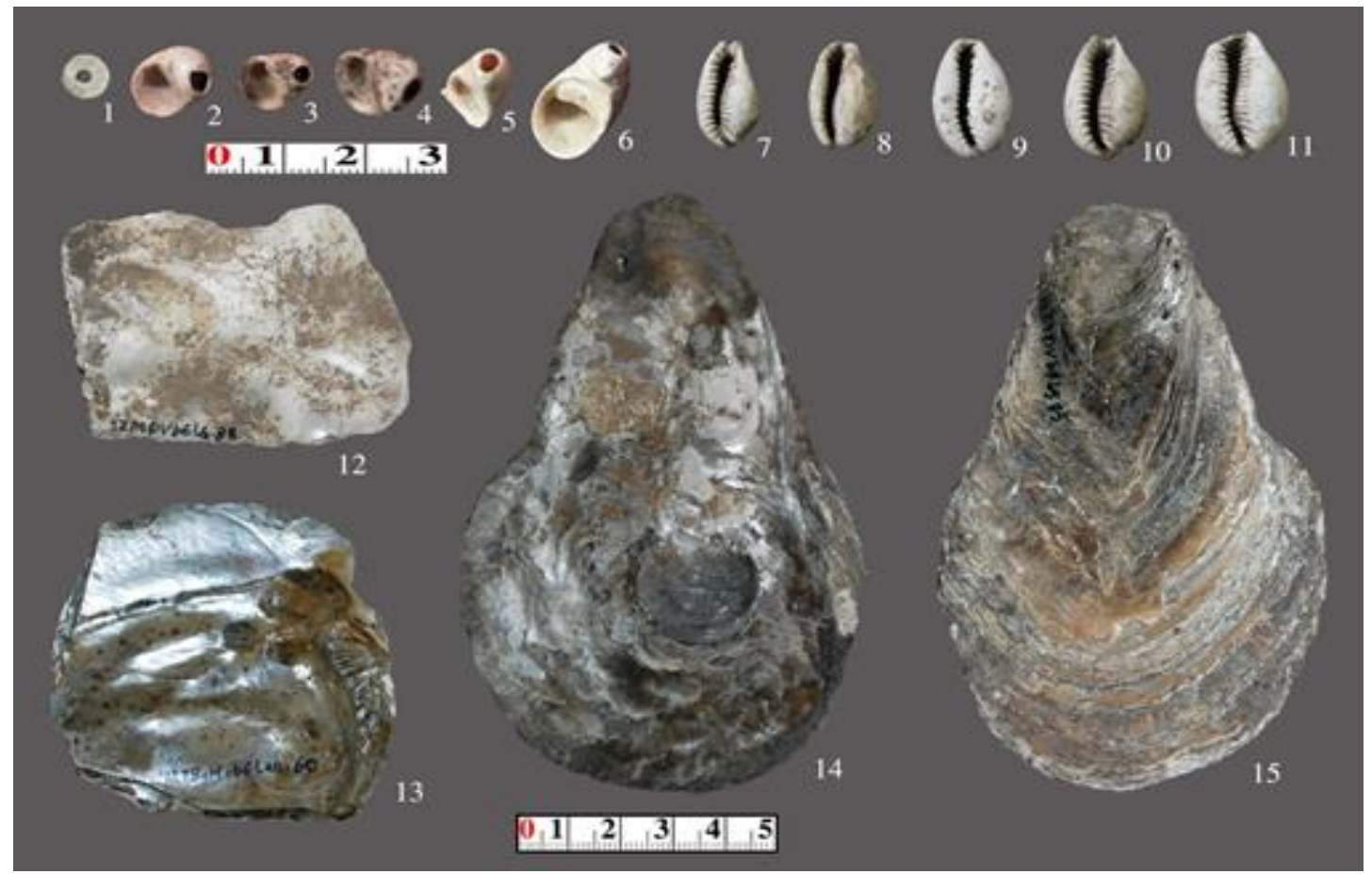

Hình 1. Đồ trang sức (1-11) và công cụ (12-15) làm từ vỏ nhuyễn thể

Nguồn: Phan (2012).

Sau 9,000 năm BP, biển tiến gần vào khu vực Tràng An, một số địa điểm thấp được con người cổ chuyển lên chỗ cao hơn. Cộng đồng cư dân Tràng An bắt đầu khai thác sản vật biển. Di tồn văn hóa biển được bảo lưu ở một số hang động nơi đây. Tại hang Mòi trên địa tầng dày $1.8 \mathrm{~m}$ nhận thấy nhuyễn thể nước ngọt có tuổi từ $12,640 \pm 35$ năm $\mathrm{BP}$ (lớp 11) đến 9,555 \pm 30 năm $\mathrm{BP}$ (lớp 8 ), còn lớp chứa xương cá biển, vỏ nhuyễn thể biển, thuộc môi trường biển có tuổi từ $8,550 \pm 30$ năm $\mathrm{BP}$ (lớp 7) đến 4,705 \pm 25 năm $\mathrm{BP}$ (lớp 4).

Trong môi trường biển, con người tiền sử đã khai thác các loài nhuyễn thể biển như vọp (Geloina coaxans), hàu cửa sông (Crassostrea rivularis), ốc (undata sp), ốc mỏ 
két, ốc viền vàng, ốc mít, sò huyết, ngó, ngao dầu, và đánh bắt một số loài cá biển. Cư dân ở đây vẫn duy trì hoạt động săn bắt các loài động vật trên cạn như: Trâu, bò rừng, hươu, nai, hoẵng, lợn rừng, gấu, khỉ, nhím, chim, và rùa như giai đoạn trước. Số lượng các loài thì nhiều, nhưng số lượng cá thể trong một loài thì ít. Điều này phản ánh hoạt động kinh tế khai thác là đa tạp, mỗi loài một ít đã đảm bảo sự cân bằng sinh thái.

Trong môi trường lục địa trước 10,000 năm $\mathrm{BP}$, ở Tràng An chưa xuất hiện đồ gốm. Đến giai đoạn sau 9,000 năm BP, ở một số di tích như: Mái đá Ốc, Mái đá Vàng, hang Mòi (lớp 6A), và Thung Bình đã xuất hiện đồ gốm. Trong đó, ở lớp 6A hang Mòi có gốm thô có văn thừng đập tìm thấy trong lớp có niên đại 7,381 năm BP đến 7,186 năm TCN, hoặc ở di tích Mái đá Vàng, niên đại $8,720 \pm 235$ năm BP, và ở Mái đá Ốc có tuổi $8,410 \pm 295$ năm BP. Như vậy, đồ gốm xuất hiện ở Tràng An vào khoảng 9,000 năm $B P$ là gốm thô hiện biết cổ nhất ở Việt Nam và Đông Nam Á. Tư liệu trên minh chứng cho quan điểm, chỉ có cư dân sống định cư và làm nông nghiệp mới là người phát minh ra đồ gốm là không có cơ sở. Một số mảnh gốm ở Tràng An có vết ám khói, chúng được sử dụng để đun nấu và làm chín món ăn thủy sản, do đó, gốm cũng gắn liền với cư dân khai thác và chế biến hải sản. Ngoài ra, rất có thể, đồ gốm ra đời còn xuất phát từ nhu cầu trữ nước ngọt để đi biển và chế biến thức ăn từ hải sản biển, nhất là chế biến cá ở dạng vi sinh.

Trong điều kiện bị nước biển cô lập thành hòn đảo, cư dân cổ Tràng An sử dụng đá vôi (loại delomit) có độ cứng cao hơn đá vôi thông thường để chế tác công cụ. Ngoài ra, cư dân cổ nơi đây còn dùng để trao đổi nguyên liệu đá cứng hơn ở ngoài hòn đảo để làm rìu mài lưỡi, chày, bàn nghiên, và bàn mài. Đặc biệt, cư dân ở đây đã sử dụng vỏ nhuyễn thể biển có kích thước lớn có sã̃n trong tự nhiên làm công cụ cắt, nạo, làm đồ đựng như vỏ hàu (Crassostrea rivularis), vọp (Geloina coaxans), ngao dầu (Meretrix meretrix), hoặc làm đồ trang sức từ vỏ ốc tiền (Cypraea annulus).

Đứng trước biển, người cổ Tràng An đã chế tác ra tổ hợp công cụ lao động có chất liệu đá vôi, duy trì kỹ thuật ghè đẽo, và sớm nảy sinh kỹ thuật mài. Họ chế tạo và sử dụng phổ biến đồ gốm văn đập, đồng thời triển khai các hoạt động khai thác nguồn lợi từ rừng, biển, hoặc đầm lầy xung quanh, thay đổi về kỹ thuật chế tác công cụ, và từng bước thích ứng với môi trường tự nhiên xung quanh đã làm nên một sắc thái văn hóa biển riêng và sớm nhất hiện biết ở Việt Nam. Trong một nghiên cứu, Nguyễn, K. (2012, tr. 20-30) đánh giá cao yếu tố phát minh ra đồ gốm của cư dân cổ Tràng An, đây là đồ gốm xuất hiện sớm nhất ở Việt Nam, khoảng 9,000 năm $\mathrm{BP}$. Đồ gốm đóng vai trò quan trọng trong trữ nước ngọt, bảo quản, và chế biến các loài hải sản trong môi trường khai thác biển của cư dân tiền sử Tràng An.

Nhìn chung, những cư dân sống trong giai đoạn 12,000 năm BP đến 7,000 năm BP chịu tác động mạnh mẽ của những biến động khí hậu và môi trường, đó là thời kỳ mưa nhiều và lạnh đột ngột. Kết quả phân tích độ từ cảm (magnetic susceptibility), trầm tích trong một số hang động như hang Con Moong (Thanh Hóa), hang Chổ (Hòa Bình), hang Thung Bình, Mái đá Ông Hay (Ninh Bình), và Lán Mỏ (Sơn La) cho thấy giai đoạn từ 20,000 năm $\mathrm{BP}$ đến 7,000 năm $\mathrm{BP}$ ở Bắc Việt Nam có các chu kỳ nóng ẩm xen kẽ với các chu kỳ lạnh hoặc mát hơn. Trong đó, giai đoạn 11,400 năm BP đến 8,800 năm BP là 
thời kỳ mưa nhiều nhất, bằng chứng là tỷ lệ trầm tích đưa vào các hang động ở thời điểm này tăng gấp 10 lần giai đoạn trước và sau đó, tương ứng đó là lượng mưa cũng tăng ngần ấy lần (Lưu, Ellwood, \& Nguyễn, 2009, tr. 410).

Một hệ quả là hầu hết cư dân giai đoạn này vào cư trú trong hang động, tiến hành khai thác các loài ốc suối (Antimelania costula) vốn phát triển cực thịnh trong tất cả các di tích hang động thuộc văn hóa Hòa Bình (Hoàng, 1984, tr. 132). Với sự gia tăng lượng mưa và khuyếch trương rừng mưa giai đoạn 18,000 năm $\mathrm{BP}$ đến 7,000 năm $\mathrm{BP}$ đã làm thay đổi một cách căn bản cổ địa lý và có ảnh hưởng sâu sắc đối với hệ sinh thái nhân văn ở Đông Nam Á giai đoạn Holocene sớm (Bellwood, 1987).

\subsection{Giai đoạn 7,000 năm BP đến 4,000 năm BP}

Sau 7,000 năm BP, khi mà lượng mưa giảm đi, các nhóm cư dân tiền sử bắt đầu rời hang động, vươn ra cư trú ngoài trời, và khai thác nguồn lợi ở đồng bằng ở ven biển. Biển tiến và khí hậu ấm dần lên nên cư dân tiền sử cư trú ngoài trời trên các bãi biển và chân núi, hình thành các nền văn hóa biển tiêu biểu.

\subsubsection{Văn hoá Cái Bèo}

Phân bố ở vùng duyên hải Đông Bắc Việt Nam, niên đại từ 7,000 năm $\mathrm{BP}$ đến 5,000 năm $\mathrm{BP}$, tiêu biểu là các di tích: Cái Bèo (lớp dưới), Đồng Cẩu, Hà Lùng, Núi Hứa, và Hòn Ngò. Ngoài số lượng lớn công cụ đá ghè đẽo, trong các di tích này đã xuất hiện rìu hình mai mực, bôn tứ giác, rìu có vai mài toàn thân, và đồ gốm thô trang trí văn in dấu đan, in răng lược, các đoạn vạch ngắn, vặn thừng, và trổ lỗ thủng. Cư dân văn hóa Cái Bèo còn triển khai đánh bắt cá biển, trong các di tích còn bảo lưu khối lượng lớn xương cá biển, ít vỏ nhuyễn thể biển, và xương, cùng răng động vật trên cạn. Niên đại của cư dân Cái Bèo (lớp giữa) là $6,475 \pm 170$ năm $\mathrm{BP}$ và Hà Lùng là $6,480 \pm 40$ năm $\mathrm{BP}$. Các điểm cư trú của cư dân Cái Bèo thực sự là một làng chài cổ qua dấu tích của tổ hợp: Bếp - xương cá biển - gốm văn thừng, văn dấu đan - chì lưới, chày, và bàn nghiền. Cư dân ở đây đã sử dụng lưới vó, vận hành bằng thuyền mảng, đánh bắt cá biển, và gia công thực phẩm tại nơi cư trú. Mô thức vận hành đó khác với các cư dân cùng bình tuyến trong giai đoạn trung kỳ Đá mới như văn hóa Đa Bút, Quỳnh Văn, và Bàu Dũ (Nguyễn, 2009, tr. 246).

\subsubsection{Văn hoá Đa Bút}

Mang tên địa điểm Đa Bút ở tỉnh Thanh Hoá, phân bố ở đồng bằng ven biển thuộc hai tỉnh Thanh Hóa và Ninh Bình, gồm các di tích: Đa Bút, cồn Cổ Ngựa, làng Còng, Bản Thuỷ, Gò Trũng (Thanh Hóa); và Đồng Vườn, hang Sáo, hang Cò, hang Mo (Ninh Bình) có các niên đại tương ứng là: $6,095 \pm 60$ năm $\mathrm{BP}, 6,390 \pm 60$ năm $\mathrm{BP}, 6,430 \pm 60$ năm BP (di tích Đa Bút) và 4,700 \pm 50 năm BP (di tích Gò Trũng) (Bùi, 1987, tr. 15-31; Nguyễn \& Nguyễn, 2004, tr. 24). Cư dân văn hóa Đa Bút phát triển nhanh kỹ thuật chế tác đồ đá, từ công cụ cuội ghè đẽo sang loại hình rìu mài lưỡi đến rìu mài toàn thẩn với kích thước nhỏ dần, cùng với các loại công cụ đá khác như đục, cưa, bàn nghiền, chày, vòng đá hình bánh xe, và đặc biệt hơn là chì lưới đánh cá hình quả nhót có khía rãnh để 
buộc dây. Người cổ Đa Bút ổn định cao trong chế tác đồ gốm, đó là nồi đáy tròn, miệng thẳng hoặc hơi loe, thành miệng cao, bụng hình cầu, và kích thước $30-40 \mathrm{~cm}$. Khắp mặt ngoài của đồ gốm từ đáy lên tới mép miệng là những vết đập hình nan đan. Đa Bút là trung tâm chế tạo gốm văn thừng sớm nhất hiện biết ở Việt Nam. Cư dân văn hoá Đa Bút trồng một số loại cây rau củ và khai thác thuỷ sản (hến và ốc) trên sông và đầm hồ. Sang giai đoạn muộn, họ mở rộng khai thác biển (sò, điệp, cua, và cá). Văn hoá Đa Bút có nguồn gốc từ Văn hoá Hoà Bình và là tiền thân của cư dân các di tích Chân Tiên, Hoa Lộc (Thanh Hóa), và Mán Bạc (Ninh Bình).

\subsubsection{Văn hoá Quỳnh Văn}

Mang tên làng Quỳnh Văn, thuộc loại hình đống rác bếp (Kjokkenmodding). Văn hóa này hiện biết có 21 di tích, phân bố tập trung ở đồng bằng ven biển huyện Quỳnh Lưu (tỉnh Nghệ An), niên đại C14 (Cacbon 14) hiện biết là từ 4,785 \pm 100 năm BP (Quỳnh Văn) đến 2,010 \pm 70 năm BP (Cồn Đất) (Nguyễn, T., 1998, tr. 48). Cư dân văn hóa Quỳnh Văn chế tác công cụ chủ yếu là ghè đẽo, tạo công cụ không định hình, và hiếm gặp rìu mài toàn thân. Người cổ ở đây chủ yếu chế tạo nồi gốm đáy nhọn, xương gốm dày và thô, kích thước của các đồ gốm lớn, và trang trí hoa văn in đập. Sang giai đoạn muộn thì xuất hiện gốm văn thừng, văn chải, và văn đập hai mặt trên các loại nồi, bình, vò, bát, và đĩa. Cư dân cổ ở đây khai thác các con điệp (Placura placenta Lin), sò gai (Arcagransa), sò nhẵn (Arcasabence Lin), hàu (Ostréa Cuculata Boru), ốc sắt (Cérilicat), cua, cá, rùa, và mực ngoài biển chất thành cồn lớn. Ngoài ra, cư dân cổ Quỳnh Văn còn tiến hành săn bắt động vật trên cạn, nhưng chưa có dấu hiệu trồng trọt và chăn nuôi. Tư liệu cho thấy, cư dân văn hóa Quỳnh Văn phát triển sang văn hóa Bàu Tró thông qua loại hình văn hóa Thạch Lạc.

\subsubsection{Di tích Bàu Dũ}

Di tích Bàu Dũ ở xã Tam Xuân, một xã ven biển thuộc huyện Núi Thành (Quảng Nam). Di tích Bàu Dũ được khai quật vào các năm 1984, 2013, và 2014, có niên đại 5,510 \pm 60 năm $\mathrm{BP}$. Cư dân Bàu Dũ sống định cư ở ven biển, chế tác công cụ đá bằng kỹ thuật ghè hai mặt, tạo ra những chiếc rìu hình hạnh nhân, nạo hình đĩa, rìu ngắn, công cụ chặt thô, cùng chày, bàn nghiền, và hòn kê. Đồ gốm có gốm thô được trang trí hoa văn khắc vạch. Người cổ Bàu Dũ triển khai hoạt động khai thác biển như đánh bắt cá, thu lượm các loài sò điệp, và săn bắt một số động vật trên rừng. Tổ hợp công cụ đá ở Bàu Dũ mang đậm truyền thống của văn hóa Hòa Bình, song hoạt động kiếm sống ở đây diễn ra trong môi trường ven biển, chủ yếu là khai thác biển (Vũ \& Trịnh, 1986, tr. 16).

Như vậy, trên lãnh thổ Việt Nam, các nhóm cư dân thời tiền sử tiếp cận với biển ở các địa phương khác nhau. Tùy thuộc vào đặc điểm sinh thái ở mỗi vùng mà tạo dựng một hình thức sinh kế biển khác nhau. Đối với cư dân văn hóa Cái Bèo sống ở vùng duyên hải Đông Bắc thì thiên về đánh cá biển. Người Đa Bút sống ở đồng bằng ven biển Bắc Trung Bộ chuyển dần từ khai thác nhuyễn thể sông sang đánh bắt cá biển và thu lượm nhuyê̂n thể biển. Trong khi đó, người Quỳnh Văn chiếm cư vùng biển nông ở khu vực Quỳnh Lưu thì thiên về khai thác sò điệp thuộc đới ven bờ (Hoàng, 1966). Thực chất đây 
là cơ sở hình thành các vùng kinh tế - xã hội khác nhau trong thời tiền sử ở Việt Nam (Nguyễn, 2003, tr. 88).

\subsection{Giai đoạn 4,000 năm BP đến 3,000 năm BP}

Giai đoạn 4,000 năm BP đến 3,000 năm BP ở đồng bằng ven biển về cơ bản là thời kỳ biển lùi, hình thành các thềm biển và doi đất cao $3.5 \mathrm{~m}$ đến $4.0 \mathrm{~m}$ so với chung quanh. Tiếp sau đó là thời điểm biển lấn $(3,000$ năm $\mathrm{BP}$ đến 2,000 năm $\mathrm{BP})$, biển mở rộng trở lại gần như ngày nay (Trần, 2003, tr. 47). Đây là giai đoạn hình thành các nền văn hóa, nhóm văn hóa hậu kỳ Đá mới - sơ kỳ Kim khí, và có một số văn hóa tiêu biểu.

- Văn hoá Hạ Long: Có niên đại 4,000 năm BP đến 3,000 năm BP, với các di tích tiêu biểu như: Đồng Mang, Ngọc Vừng, Xích Thổ, Quất Đông Nam, Hòn Gai, Tuần Châu, Cái Bèo (lớp trên), Bãi Bến... phân bố chủ yếu ở vịnh Hạ Long (Andersson, 1939; Colani, 1938, tr. 93-96). Công cụ đá tiêu biểu của văn hóa Hạ Long là rìu có vai, bôn có nấc, bàn mài rãnh mặt cắt hình chữ “U”, và gốm xốp (Hà \& Nguyê̂n, 1999, tr. 122). Sống trong môi trường nước biển dâng, nhiệt độ và độ ẩm tăng, đất đai bị mặn hóa, chua phèn, và ngập lụt đã gây bất lợi cho hoạt động trồng trọt các loại cây. Trong số 28/31 địa điểm cư trú của người cổ Hạ Long là các dưng cát, bãi triều cửa sông, và chỉ có ba hang động. Các "làng chài" ở đây rộng trung bình $1,500 \mathrm{~m}^{2}$. Quy mô này nhỏ hơn "làng nông nghiệp" và có thể mật độ dân số cũng thấp hơn châu thổ Bắc Bộ (Nguyễn, K., 1998, tr. 13). Đứng trước những trở ngại đất đai bị mặn hoá, người cổ Hạ Long phát triển cao kỹ thuật chế tác đá, làm gốm, trồng cây lấy sợi, và các phương tiện vận tải trên biển để đánh bắt hải sản, trao đổi và buôn bán hàng hóa, sản vật với lục địa và các đảo xa. Những chiếc rìu bôn có vai, có nấc, và dấu Hạ Long không chỉ tìm thấy trong lục địa Bắc Việt Nam, mà còn gặp ở ven biển Quảng Đông, Phúc Kiến, hoặc Hồng Kông (Trung Quốc) (William, 1978, tr. 187). Đây là dấu hiệu về các mối quan hệ vượt biển của người Hạ Long trong quá khứ. Văn hóa Hạ Long phát triển qua hai giai đoạn: Giai đoạn sớm tương ứng với thời kỳ biển thoái, còn giai đoạn sau ứng với thời kỳ biển lấn. Niên đại C14 một số "làng chài" của văn hóa Hạ Long như sau: Ba Vũng 4,100 \pm 40 năm BP; Bãi Bến có các niên đại: 3,380 \pm 50 năm $\mathrm{BP}, 3,470 \pm 55$ năm $\mathrm{BP}, 3,180 \pm 55$ năm $\mathrm{BP}, 3,300 \pm 55$ năm $\mathrm{BP}, 3,900 \pm 80$ năm $\mathrm{BP}, 4,070 \pm 50$ năm $\mathrm{BP}, 3,090 \pm 50$ năm $\mathrm{BP}$, và $3,270 \pm 55$ năm $\mathrm{BP}$ (Nguyễn, K., 2005, tr. 3-20).

- Văn hoá Bàu Tró: Mang tên địa điểm Bàu Tró do Patte khai quật năm 1923 (Patte, 1923, tr. 409). Đến nay đã phát hiện được hơn 20 di tích, phân bố ở đồng bằng ven biển từ tỉnh Nghệ An đến Quảng Bình, niên đại của văn hóa Bàu Tró từ 4,500 năm $\mathrm{BP}$ đến 3,000 năm $\mathrm{BP}$ (Phạm, 2000, tr. 35). Người cổ Bàu Tró chế tạo và sử dụng rìu, bôn, cuốc, đục, dao, cưa, mũi khoan, bàn mài, chày, bàn nghiền, và hòn ghè. Đồ gốm có bình gắn tai ở thành miệng, nồi miệng loe, mép vê cuốn hình con sâu, trang trí hoa văn in mai rùa, hình khuông nhạc trên nền thừng, và tô màu đỏ, đen ánh chì. Hoạt động sống của 
người cổ Bàu Tró là săn bắt, hái lượm, đánh cá, và làm nông nghiệp. Kỹ thuật chế tác công cụ đá đạt tới đỉnh cao. Nhìn chung, cư dân văn hóa Bàu Tró đã chiếm cư vùng đồng bằng ven biển, làm chủ các bầu nước ngọt, giao lưu rộng mở với các bộ tộc đồng đại, và góp phần hình thành văn hoá Tiền Sa Huỳnh và Sa Huỳnh ở miền Trung Việt Nam, và văn hóa Tiền Đông Sơn và Đông Sơn ở lưu vực sông Cả.

Cùng bình tuyến với Văn hóa Hạ Long và Bàu Tró, ở Việt Nam còn có các văn hóa biển như: Hoa Lộc (Thanh Hóa), Bình Châu - Long Thạnh (Quảng Ngãi), và Xóm Cồn (Khánh Hòa). Các văn hóa này về cơ bản thuộc thời đại Đồng Thau, có niên đại từ 4,000 năm BP đến 3,000 năm BP.

- Văn hóa Hoa Lộc: Mang tên địa điểm phát hiện ở xã Liên Lộc, huyện Hậu Lộc (Thanh Hóa), có niên đại 3,500 năm BP. Cư dân văn hóa Hoa Lộc sống định cư, làm nông nghiệp dùng cuốc, và phát triển đỉnh cao kỹ thuật chế tác đồ đá và đồ gốm. Những lưỡi cuốc đá có vai kích thước lớn, những chiếc rìu tứ giác to thô, những viên đá có vết khắc ngang, những con dấu bằng đất nung có hoa văn hình học, khuyên tai hình "con đỉa", nồi miệng đa giác, và các hộp hình nghiên mực là những di vật tiêu biểu cho văn hóa Hoa Lộc (Phạm, 1999, tr. 26). Cư dân văn hóa biển Hoa Lộc có quan hệ giao lưu trao đổi với cư dân nằm trong lục địa như: Cồn Chân Tiên (Thanh Hóa), Ghệ Dạ (Phú Thọ), Bản Gièm (Sơn La), đặc biệt là cư dân văn hóa biển Hạ Long (Quảng Ninh), Thạch Lạc (Hà Tĩnh), Bàu Tró (Quảng Bình), và với cả cư dân tiền sử ở Đài Loan, Phúc Kiến (Trung Quốc).

- Văn hóa Long Thạnh - Bình Châu: Tiêu biểu cho hai giai đoạn sơ và hậu kỳ Đồng thau ở vùng biển tỉnh Quảng Ngãi có di tích Long Thạnh ở Đức Phố, tương đương với lớp dưới Xóm Ốc, Bãi Ông, và Vườn Đình - Khuê Bắc. Đặc trưng di tích và di vật là chum mộ hình trứng hay hình cầu, chôn ở nơi cư trú, được chôn theo đồ gốm, đồ đá, và không gặp đồ đồng. Đây là niên đại sơ kỳ Đồng thau. Di tích Bình Châu ở Bình Sơn, tương đương với lớp trên Xóm Ốc, Bàu Trám, mộ táng tách khỏi nơi cư trú, có dạng huyệt đất, chôn theo đồ đồng như lao, mũi tên, đục, và lưỡi câu. Đồ gốm có bình vai gãy, bát chân cao, và khuyên tai hình "con đỉa". Trong đó, bình gốm vai gãy có đáy thon nhọn và bát bồng chân hình ống trụ là những di vật tiêu biểu của văn hóa này. Đây là nền văn hóa biển, trực tiếp phát triển lên văn hóa Sa Huỳnh ở Trung Bộ Việt Nam (Hán, 2008, tr. 205).

- Văn hóa Xóm Cồn: Mang tên di tích Xóm Cồn ở Cam Ranh (Khánh Hòa), niên đại 3,500 năm BP đến 3,000 năm BP. Văn hóa Xóm Cồn gồm các di tích phân bố ven biển như Xóm Cồn, Cù Hin, hoặc ngoài đảo như Hòn Tre, Hòn Mun, và Hòn Tầm. Công cụ đá đặc trưng là những chiếc rìu tứ giác bằng đá, đồ trang sức làm bằng vỏ ốc Tridacna, Tubo, ốc cối, đồ gốm có bàn đập, hòn kê, và bát bồng chân cao, có hoa văn trang trí là khắc vạch và gốm màu. Các sản vật biển của cư dân văn hóa Xóm Cồn được trao đổi với các vùng 
khác như Biển Hồ (Gia Lai), Hoa Lộc (Thanh Hóa), và xa hơn nữa là với cư dân tiền sử Nhật Bản hoặc các đảo khác ở Thái Bình Dương (Vũ, 1999).

Ngoài các văn hóa nói trên, ở vùng biển Việt Nam đã xuất hiện một số di tích thời đại Đồng thau, tiêu biểu như: Bồ Chuyến (Quảng Ninh), Mán Bạc (Ninh Bình), Cù Lao Chàm (Quảng Nam), Cù Lao Ré (Quảng Ngãi), Văn Tứ Đông (Khánh Hòa), Mỹ Tường, Hòn Đỏ (Ninh Thuận), Bàu Hòe (Bình Thuận), Thổ Chu (Kiên Giang), và Côn Đảo (Bà Rịa - Vũng Tàu). Đây là giai đoạn lan tỏa và chiếm cư hầu hết các đảo ven bờ của cư dân văn hóa biển trong tiền sử Việt Nam. Những cư dân biển thời này giao lưu với các nhóm cư dân nằm sâu trong lục địa. Một số mô típ hoa văn gốm Phùng Nguyên, Xóm Rền (Phú Thọ) tìm thấy trên gốm Bồ Chuyển (Quảng Ninh), gốm lớp trên Cái Bèo (Hải Phòng), gốm Mán Bạc (Ninh Bình), và gốm Bình Châu (Quảng Ngãi). Ngược lại, bàn xoa làm gốm ở Mán Bạc (Ninh Bình) lại tìm thấy ở tận Suối Linh (Đồng Nai) và Phù Mỹ (Lâm Đồng). Không chỉ thế, cư dân thời này còn quan hệ với các nhóm cư dân trên các đảo Thái Bình Dương như Đài Loan (Trung Quốc), Philipines, và Indonesia qua dấu tích công cụ, đồ trang sức, đồ gốm, và các hoạt động sinh kế biển khác.

\subsection{Dấu ấn văn hóa biển Việt Nam giai đoạn sau 3,000 năm BP}

Bước vào thời đại Đồ Sắt, dấu tích các nền văn hóa Đông Sơn ở Bắc Bộ, Sa Huỳnh ở Trung Bộ, và Tiền Óc Eo ở Nam Bộ đã in những mảng màu đậm nhạt khác nhau trên bản đồ văn hóa biển Việt Nam.

- Dấu ấn văn hoá Đông Son: Có trống đồng, rìu đồng, giáo đồng, và cả mộ thuyền Đông Sơn có mặt ở vùng Thủy Nguyên (Hải Phòng) và trên một số đảo vịnh Hạ Long. Những di vật Đông Sơn ở đây không chỉ từ lục địa ra, mà vết tích Tiền Đông Sơn đã bám rễ ở vùng biển từ trước đó. Khi khai quật hang Bồ Chuyến (Hoành Bồ), người ta đã tìm thấy vết tích cư trú của cư dân sử dụng rìu tứ giác, cưa đá, và đồ trang sức bằng đá néphrite giống hệt văn hóa Phùng Nguyên, cùng gốm xốp, miệng cụp, và thành gờ cao phía ngoài giống gốm Tràng Kênh (Hải Phòng) (Bùi, 2001, tr. 245). Khai quật di chỉ Đầu Rằm (Yên Hưng, Quảng Ninh) và Bãi Bến (đảo Cát Bà, Hải Phòng), các nhà khảo cổ học đã tìm thấy rìu bôn tứ giác, đục, lưỡi cưa, mũi khoan, mũi lao, vòng tay, khuyên tai, và hạt chuỗi hình ống được làm từ các loại đá màu khá đẹp, ngoài ra còn có cả những mũi khoan kiểu Tràng Kênh và chiếc bình gốm đế vuông trang trí đồ án khắc vạch hình chữ "S", có phần ngăn đệm hình tam giác kiểu Phùng Nguyên. Điều lý thú là, lớp trên di chỉ Đầu Rằm đã tìm thấy di tích văn hoá Đông Sơn (Phạm, 2003, tr. 28). Đây là dấu ấn văn hóa Đông Sơn biển, cùng với Đông Sơn núi, và Đông Sơn đồng bằng châu thổ tạo dựng nên nền văn minh Việt cổ, cơ tầng của quốc gia Văn Lang - Âu Lạc. Có thể nói, cư dân biển đóng vai trò quan trọng trong quá trình hình thành quốc gia dân tộc.

- Văn hoá Sa Huỳnh: Là văn hóa biển tiêu biểu ở vùng cửa sông và ven biển ở các tỉnh Quảng Nam, Quảng Ngãi, và Phú Yên. Bên cạnh các di tích cư trú, các nhà khảo cổ đã tìm thấy các loại hình mộ táng đặc trưng cho văn hóa $\mathrm{Sa}$ 
Huỳnh là những chiếc chum được chôn đứng và chôn theo công cụ sắt, đồ trang sức bằng thuỷ tinh, mã não, hoặc đồ gốm. Cư dân văn hóa Sa Huỳnh chiếm cư hầu hết bờ biển và các đảo từ Trung Trung Bộ tới Nam Trung Bộ niên đại từ giữa thiên niên kỷ I TCN đến thế kỷ I và II SCN (Chử, 2004, tr. 727-740). Các nhà khảo cổ Việt Nam cho rằng, văn hóa Sa Huỳnh có nguồn gốc bản địa, phát triển trực tiếp từ văn hóa biển Long Thạnh - Bình Châu, dạng Nguyên Sa Huỳnh (Proto Sahuynhian), trước đó còn có các di tích dạng nguồn hợp lên Sa Huỳnh nhưng không trực tiếp, và dạng Tiền Sa Huỳnh (Pre Sahuynhian) như Bàu Tró, Xóm Cồn, và Biển Hồ. Văn hóa Sa Huỳnh là văn hóa biển, song có quan hệ với cư dân Lung Leng (Kon Tum), cư dân Bãi Cọi (Hà Tĩnh) (Bảo tàng Quốc gia Hàn Quốc \& Bảo tàng Lịch sử Quốc gia Việt Nam, 2014, tr. 217-218), các di tích Xóm Ốc trên đảo Lý Sơn (Quảng Ngãi) (Đoàn, 2004, tr. 771-792), Cao Cát ở đảo Phú Quý (Bình Thuận), Hòn Cau, cồn Hải Đăng, cồn Miếu Bà, đảo Cồn Cỏ (Bà Rịa - Vũng Tàu), Bãi Dong (đảo Thổ Chu), di tích Hòn Tre, Bãi Nhã, Bãi Ngự ở đảo Nam Du (Kiên Giang) (Nguyễn, 2015, tr. 517). Người Sa Huỳnh sử dụng phổ biến đồ sắt, song cho đến nay vẫn chưa tìm thấy các trung tâm luyện sắt ở các tỉnh ven biển Trung Bộ. Có nhiều khả năng những đồ sắt của người cổ Lung Leng được các thương nhân Sa Huỳnh buôn bán trao đổi đến các vùng biển Nam Trung Bộ và xa hơn thế. Vào giai đoạn phát triển cao, văn hóa Sa Huỳnh ảnh hưởng đển Tây Nguyên, trong khi đó người Sa Huỳnh lại tiếp nhận các yếu tố Kalanay tạo nên truyền thống Sa Huỳnh - Kalanay chỉ vùng biển mà không lan tới Tây Nguyên.

- Văn hóa Giồng Phệt (hay văn hóa Cần Giờ): Ở huyện Cần Giờ, Thành phố Hồ Chí Minh, tiêu biểu là các di tích Giồng Phệt, Giồng Cá Vồ, Long Bửu, và Giống $\mathrm{Am}$. Các di tích nói trên có thể lập thành một văn hóa khảo cổ, mang tên văn hóa Giồng Phệt, niên đại đoán định khoảng 2,500 năm BP đến 2,000 năm BP (Đặng \& Vũ, 1995, tr. 18; Nguyễn, T., 2012). Các di tích trong văn hóa Giồng Phệt vừa là nơi cư trú (giai đoạn sớm) vừa là nơi để mộ táng (giai đoạn muộn). Cư dân Giồng Phệt là những người khai thác nguồn lợi biển, đồng thời là nơi chế tạo đồ gốm, đặc biệt là chế tạo đồ trang sức bằng đá bán quý, thủy tinh, và vỏ nhuyễn thể biển. Người Giồng Phệt mai táng thân nhân bằng cách đặt ngồi bó gối trong các chum lớn, có một số được cải táng, hoặc chôn trong mộ đất. Văn hóa Giồng Phệt có thể phát triển từ nhóm di tích Bến Đò, Hội Sơn, và phát triển lên văn hóa Óc Eo, có quan hệ mật thiết với văn hóa $\mathrm{Sa}$ Huỳnh và với cư dân đương thời ở Philippines, Campuchia, và Thái Lan. Niên đại C14 trong Hố khai quật 1 ở Giồng Cá Vồ, độ sâu $1.5 \mathrm{~m}$ có tuổi $2,480 \pm 50$ năm $\mathrm{BP}$, Giống $\mathrm{Am}$ có tuổi $1,665 \pm 40$ năm $\mathrm{BP}$. Trong lịch sử, có thể người Sa Huỳnh đã từng tồn tại những "cảng thi $s o$ " khai" trong đó có Hội An và Cần Giờ niên đại cuối thiên niên kỷ I TCN; Chính những trung tâm cảng thị ấy đã chứng kiến từ Sa Huỳnh tới Chăm, từ Giồng Phệt và Giống Cá Vồ tới Óc Eo (Ngô, 1997, tr. 45-57). Các cộng đồng cư dân Tiền Óc Eo, Óc Eo, và Hậu Óc Eo ở đồng bằng Nam Bộ, từ giữa thiên niên kỷ I TCN đến thế kỷ X SCN có sự tương thích nhất định với sự dao động 
mực nước biển Holocene muộn. Nền văn minh Óc Eo phát triển đỉnh cao, là cơ tầng của vương quốc Phù Nam ở thế kỷ I đến thế kỷ VII, và tập trung cao ở vùng Tứ giác Long Xuyên cũng cho thấy những tác động lớn từ cổ môi trường tự nhiên đến không gian sinh tồn và đặc thù văn hóa riêng của vùng Nam Bộ (Nguyễn \& Phan, 2019, tr. 231-244).

\section{NHŨNG GIÁ TRỊ NỔI BẬT CỦA VĂN HÓA BIỂN VIỆT NAM}

Các nền văn hóa biển trong tiền - sơ sử Việt Nam là nguồn sử liệu vật chất, minh chứng cho bước chuyển từ thời đại Đồ Đá sang thời đại Kim khí; Từ tiền sử đến lịch sử, từ nguyên thủy đến văn minh với bốn giai đoạn phát triển phổ quát như sau:

- Giai đoạn tiếp cận (10,000 năm BP đến 7,000 năm BP): Là cư dân cổ văn hóa Hòa Bình - Bắc Sơn. Đây là những người đầu tiên tiếp cận biển, tiền thân của văn hóa biển trong tiền sử Việt Nam;

- Giai đoạn hình thành (7,000 năm BP đến 4,000 năm BP): Là cư dân giai đoạn trung kỳ Đá mới, tiêu biểu là các văn hóa Cái Bèo, Đa Bút, Quỳnh Văn, và Bàu Dũ vươn ra khai phá đồng bằng ven biển, khai thác nguồn lợi biển, và hình thành các trung tâm văn hóa biển tiền sử Việt Nam;

- Giai đoạn lan tỏa (5,000 năm BP đến 3,000 năm BP): Gồm một loạt các văn hóa giai đoạn hậu kỳ Đá mới và sơ kỳ Đồng thau hình thành và phát triển ở các vùng biển khác nhau như: Văn hóa Hạ Long (ở vùng biển Đông Bắc), Hoa Lộc, Thạch Lạc, Bàu Tró (ở ven biển Bắc Trung Bộ), Long Thạnh - Bình Châu (ở ven biển Trung Trung Bộ), Xóm Cồn (ở Nam Trung Bộ), cùng một loạt di tích đồng đại khác ở các đảo ven bờ như: Cồn Cỏ, Lý Sơn, Hòn Đỏ, Bàu Hòe, Thổ Chu, và Côn Đảo;

- Giai đoạn hội nhập (3,000 năm BP đến 2,000 năm BP): Có các văn hóa biển giai đoạn hậu kỳ Đá mới và sơ kỳ Kim khí hội nhập với các văn hóa miền núi, cao nguyên, và có các luồng di cư từ trên biển Thái Bình Dương tạo dựng nên ba nền văn hóa thời đại Sắt sớm ở Việt Nam như: Văn hóa Đông Sơn ở Bắc Bộ, văn hóa Sa Huỳnh ở Trung Bộ, và văn hóa Cần Giờ ở Nam Bộ.

Những tư liệu khảo cổ học tiền sử vùng biển Việt Nam là cơ sở cho việc nghiên cứu về địa môi trường, cổ khí hậu, sự thay đổi đường bờ do biển tiến, biển thoái, cũng như các biến cố của thiên nhiên trên biển. Kết quả nghiên cứu cho thấy, đặc trưng các phổ phấn hoa và biến động độ từ cảm trên địa tầng các di tích khảo cổ có niên đại C14 là tài liệu lý tưởng cho việc nghiên cứu cổ môi trường giai đoạn cuối Cánh Tân đầu Toàn Tân ở Việt Nam. Lịch sử hình thành địa chất vùng biển gắn liền với biển tiến, biển thoái, và không thể tách rời các di tích cư trú của người Tiền sử ở ven biển và hải đảo. Mới đây, nghiên cứu về quá trình thành tạo, quy mô, và tuổi các di tích khảo cổ thuộc loại hình cồn sò, điệp của văn hóa Quỳnh Văn và văn hóa Thạch Lạc ở ven biển Nghệ An - Hà Tĩnh. Các nhà địa vật lý đã ghi nhận ba lần động đất, sạt lở sườn núi, và sóng thần lớn vào các thời kỳ 4,600 năm $B P$ đến 4,300 năm $B P, 4,100$ năm $B P$ đến 4,000 năm $B P$, và 600 năm 
BP đến 80 năm BP (Ngô, Cao, \& Lê, 2011, tr. 129) đã minh chứng cho những biến động về mặt tự nhiên đã tác động đến hoạt động sống của cư dân tiền sử.

Những dấu tích văn hóa biển tiền sử Việt Nam còn giúp chúng ta tìm hiểu bức tranh ngôn ngữ tộc người trong quá khứ. Hiện nay, các nhà ngôn ngữ thừa nhận Đông Nam Á tồn tại ba ngữ hệ lớn là Nam Á, Nam Đảo, và Tày Thái. Schmitdt (1906) cho rằng có một ngữ hệ Austric rộng lớn chung cho cả Đông Nam Á. Theo Hà (1993, tr. 2), ngữ hệ Austric này chỉ có thể liên hệ với văn hóa Hòa Bình, một vạn năm trước, phân bố rộng khắp Đông Nam Á. Các nghiên cứu này chỉ ra rằng:

- Quê hương của người Nam Đảo ở lục địa Châu Á hay hải đảo Đông Nam Á. Dựa vào phạm vi phân bố của bôn có nấc (Stepped Adze), Giáo sư Hà Văn Tấn tán thành quan điểm của Duff và cho rằng vùng phân bố của bôn có nấc là vùng phân bố của người nói ngôn ngữ Nam Đảo (Austronesian), bao gồm từ Đông Nam Trung Quốc, Đông Bắc Việt Nam, Đài Loan (Trung Quốc) đến Philippines và các đảo châu Đại Dương, đó là quê hương của người nói ngôn ngữ Nam Đảo. Còn khu vực hình thành ngôn ngữ Nam Á (Austroasiatic) có thể liên quan đến vùng phân bố cơ bản của rìu có vai là trên bán đảo Đông Dương (Hà, 1993, tr. 3);

- Bellwood (2009) và một số nhà nghiên cứu khác cho rằng cội nguồn của ngữ hệ Nam Đảo, nhánh Malayo-Polynesia đã hình thành trong nhóm cư dân nông nghiệp ở Đài Loan (Trung Quốc) vào khoảng 5,500 năm BP đến 5,000 năm $\mathrm{BP}$, họ đã di cư xuống vùng Đông Nam Á hải đảo qua Batanes tiến vào các hòn đảo của Philippines, rồi các đảo Borneo, và Palawan. Trong thời gian này, trên lãnh thổ Việt Nam chủ yếu là cư dân nói ngôn ngữ Môn-Khmer. Nhưng việc tiếp xúc thường xuyên giữa những người hải đảo Đông Nam Á với Việt Nam có thể vào 500 năm TCN.

Quá trình hình thành chủ nhân các nền văn hóa biển Việt Nam, qua nghiên cứu di cốt người ở các di tích khảo cổ cho thấy, trong giai đoạn 30,000 năm BP đến 11,000 năm BP ở Bắc Việt Nam đều tìm thấy các cốt sọ chưa phân hóa và còn đan xen hai yếu tố Mongoloid và Australoid. Đó là những người cổ sọ dài hoặc trung bình, mũi rộng, hốc mắt thấp hay trung bình, và mặt rộng. Họ sống cộng cư với những người dạng đầu tròn, hốc mắt cao, và mũi rất rộng. Trong giai đoạn 11,000 năm $\mathrm{BP}$ đến 7,000 năm $\mathrm{BP}$, do quá trình biến dị và di truyền hình thái, nhóm loại hình Indonésien cổ hình thành, phổ biến trong các di tích Hòa Bình - Bắc Sơn. Bên cạnh Indonésien cổ, ở Việt Nam còn tồn tại loại hình nhân chủng khác như Australoid, Melanesien, và hỗn chủng mà chúng ta đã gặp trong di chỉ Cái Bèo loại hình hỗn chủng Australo - Melanesien (Nguyễn, 2017). Những yếu tố mới đó có thể là là kết quả giao lưu trên biển. Sau 4,000 năm $\mathrm{BP}$, phần lớn các cốt sọ trong vùng biển Việt Nam đều mang yếu tố vàng của người Mongoloid và ngày một đậm dần. Cư dân văn hóa Hạ Long qua cốt sọ ở hang Bái Tử Long thuộc chủng tộc Mongoloid. Đi vào Quảng Ngãi, trên đảo Lý Sơn tìm thấy một số cốt sọ cổ giai đoạn Tiền Sa Huỳnh cũng thuộc chủng tộc Mongoloid. Vào sâu hơn nữa tới vùng biển Cần Giờ, trong các di tích Giồng Phệt và Giồng Cá Vồ vẫn là di cốt người thuộc chủng tộc Mongoloid. Rõ ràng, quá trình giảm đen diễn ra mạnh ở vùng biển và là cơ sở cho sự hình 
thành chủ nhân văn hóa của người Lạc Việt, rồi người Việt sau này trên lãnh thổ Việt Nam (Nguyễn, 2017, tr. 25-45).

Hiện nay, vùng biển Việt Nam đang chịu tác động của nước biển dâng cao. Theo dự báo của Bộ Tài nguyên và Môi trường Việt Nam, bước vào thế kỷ XXI nhiệt độ và mực nước đại dương đều tăng. Theo Representative Concentration Pathway (RCP) 8.5 dự đoán, đến năm 2050 nhiệt độ tăng $0.8^{\circ} \mathrm{C}$ đến $1.1^{\circ} \mathrm{C}$, lượng mưa tăng $5 \%$ đến $19 \%$. Mực nước biển Việt Nam tăng cao hơn mức trung bình toàn cầu. Đến năm 2050 là $25 \mathrm{~cm}$ (từ $17 \mathrm{~cm}$ đến $35 \mathrm{~cm}$ ), đến năm 2100 là $73 \mathrm{~cm}$ (từ $52 \mathrm{~cm}$ đến $106 \mathrm{~cm}$ ). Nếu mực nước biển dâng $100 \mathrm{~cm}$ thì có khoảng $16.8 \%$ đồng bằng sông Hồng, $1.5 \%$ các tỉnh ven biển miền Trung từ Thanh Hóa đến Bình Thuận, 17.8\% Thành phố Hồ Chí Minh, và 38\% Đồng bằng sông Cửu Long bị ngập (Bộ Khoa học và Công nghệ, 2016, tr. 28). Quan sát tại trạm Hòn Đấu Đồ Sơn, Trịnh (2007, tr. 70) cho biết trong vòng 32 năm qua (1957 đến 1989) mực nước Biển Đông đã tăng $2.24 \mathrm{~mm} /$ năm. Bài học ứng xử với môi trường biển đảo của cư dân tiền sử trong quá trình bảo tồn và phát triển văn hóa của chúng ta hẳn có giá trị.

Tóm lại, mực nước dâng sẽ làm mất đi các di tích khảo cổ thời tiền sử như đã từng thấy ở vịnh Hạ Long trong giai đoạn cuối Pleistocene. Rồi đây, nước biển lại dâng cao $1 \mathrm{~m}$, lan rộng thêm, là nguy cơ vùi lấp các di tích thuộc phạm trù các văn hóa biển. Thêm nữa, hàng loạt các dự án và công trình vẫn thi nhau phá núi, san đồi, và lấp biển làm các công trình đồ sộ, khiến cho không ít di tích bị phá hủy vĩnh viễn. Có thể nói, mỗi di tích khảo cổ học là một pho sử biên niên và là thẻ căn cước của dân tộc để bước vào sân chơi của thế giới hội nhập. Làm mất di tích là tự đánh mất mình giữa biển khơi, như người mất trí nhớ, không thể đưa con thuyền Việt Nam tới bến bờ thắng lợi. Rõ ràng, các di tích văn hóa biển tiền sử Việt Nam có vị trí đặc biệt quan trọng trong tiến trình phát triển kinh tế - xã hội của Việt Nam, cần được nghiên cứu, bảo vệ, và phát huy.

\section{TÀI LIỆU THAM KHẢO}

Andersson, J. G. (1939). Archaeological research in the Fai Tsi Long Archipelago, Tonkin. The Museum of Far Eastern Antiquities Stockholm Bulletin, 11, 11-27.

Bảo tàng Quốc gia Hàn Quốc \& Bảo tàng Lịch sử Quốc gia Việt Nam. (2014). Di tích Bãi Cọi Hà Tĩnh, Việt Nam. Bài báo được trình bày tại Hội thảo Hợp tác Nghiên cứu Học thuật Hàn - Việt, Hà Nội, Việt Nam.

Bellwood, P. (1987). Man's conquest of the Pacific. Auckland, New Zealand: Harper Collins Publisher.

Bellwood, P. (2009). The origins and migrations of the ancestral Austronesian - speaking peoples. Paper presented at The International Symposium for 100 Years Discovery and research of the Sa Huynh Culture, Quangngai, Vietnam.

Bộ Khoa học và Công nghệ. (2016). Tóm tắt kịch bản biến đổi khí hậu nước biển dâng cho Việt Nam. Hà Nội, Việt Nam.

Bùi, V. (1987). Đa Bút - văn hóa và văn minh. Tạp chí Khảo cổ học, (3), 15-31. 
Bùi, V. (2001). Nhân phát hiện hang Bồ Chuyến (Quảng Ninh) nhìn lại nhóm di tích Phùng Nguyên ở ven biển Đông Bắc. Bài báo được trình bày tại Hội thảo Tìm hiểu văn hoá Phùng Nguyên, Phú Thọ, Việt Nam.

Chử, V. T. (2004). Văn hoá Sa Huỳnh - nhìn lại 10 thập kỷ phát hiện và nghiên cứu. Trong Viện khảo cổ học, Một thế kỷ khảo cổ học Việt Nam (Tập 1, tr. 727-740). Hà Nội, Việt Nam: NXB. Khoa học Xã hội.

Colani, M. (1938). Découvertes Préhistoriques dans les parages de la Baie d'Along. Dans Institut Indochinois pour l'Etude de l'Homme, (1), 93-96.

Đặng, V. T., \& Vũ, Q. H. (1995). Khai quật di chỉ Giồng Cá Vồ (Cần Giờ), TP. Hồ Chí Minh. Tạp chí Khảo cổ học, (2), 3-19.

Đoàn, N. K. (2004). Vai trò của các đảo ven bờ và vùng duyên hải trong nghiên cứu văn hoá Sa Huỳnh ở miền Trung Việt Nam. Trong Viện khảo cổ học, Một thế kỷ khảo cổ học Việt Nam (Tập 1, tr. 771-792). Hà Nội, Việt Nam: NXB. Khoa học Xã hội.

Hà, H. N., \& Nguyễn, V. H. (1999). Ha Long thời tiền sủ. Quảng Ninh, Việt Nam: Ban Quản lý vịnh Hạ Long.

Ha, V. T. (1985). The late pleistocene climate in the Southeast Asia: New data from Vietnam. Dans Moderm Quaternary Research in Southeast Asia, 9, 81-86.

Hà, V. T. (1993). Văn hóa và ngôn ngữ ở Việt Nam thời tiền sử. Tạp chí Khảo cổ học, (1), 1-6.

Hà, V. T., Nguyễn, K. S., \& Trình, N. C. (1998). Văn hóa Sơn Vi. Hà Nội, Việt Nam: NXB. Khoa học Xã hội.

Hán, V. K. (2008). Co sở khảo cổ học. Hà Nội, Việt Nam: NXB. Đại học Quốc gia Hà Nội.

Hoàng, K. C. (1984). Động vật thân mềm (Mollusca) trong các di tích hang động Hòa Bình - Bắc Sơn. Tạp chí Khảo cổ học, (4), 132-135.

Hoàng, X. C. (1966). Hệ thống di chỉ vỏ sò điệp ở Quỳnh Luu. Bài báo được trình bày tại Hội thảo Một số Báo cáo Khảo cổ học Việt Nam, Hà Nội, Việt Nam.

Lê, Đ. A., \& Trần, Đ. T. (2011). Vị thế Biển Đông. Bài báo được trình bày tại Hội nghị Khoa học và Công nghệ Biển Toàn quốc Lần thứ $\mathrm{V}$, Hà Nội, Việt Nam.

Lưu, T. P. L., Ellwood, B. B., \& Nguyễn, C. T. (2009). Chu kỳ Younger Dryas trong số liệu từ cảm tại hang Con Moong (Thanh Hoá). Tạp chí các Khoa học về Trái đất, 31(4), 410-417.

Ngô, G. T., Cao, Đ. T., \& Lê, D. B. (2011). Nhũng dấu tích địa chất có thể là tàn dư của sóng thần ở vùng biển Nghẹ - Tĩnh. Bài báo được trình bày tại Hội nghị Khoa học và Công nghệ Biển Toàn quốc Lần thứ $\mathrm{V}$, Hà Nội, Việt Nam.

Ngô, T. P. (1997). Văn hóa Sa Huỳnh trong khung cảnh Đông Nam Á. Tạp chí Khảo cổ hoc, (4), 45-57. 
Nguyễn, A. T., \& Nguyễn, L. C. (2018). Quần động vật Cánh Tân ở hang Thánh Hóa. Trong T. T. Tống \& L. C. Nguyễn, Đến với vùng văn hóa Kinh Môn. Hà Nội, Việt Nam: NXB. Khoa học Xã hội.

Nguyễn, K. S. (1995). Biển với cư dân tiền sử vùng Đông Bắc. Tạp chí Khảo cổ học, (4), 6-14.

Nguyễn, K. S. (1997). Văn hoá biển tiền sử Việt Nam - một mô hình giả thiết. Tạp chí Khảo cổ học, (3), 16-28.

Nguyễn, K. S. (1998). Dân số học tiền sử - một tiếp cận mới của Khảo cổ học Việt Nam. Tạp chí Khảo cổ học, (4), 3-15.

Nguyễn, K. S. (2003). Văn hóa Đa Bút với vấn đề phân vùng kinh tế - xã hội đầu tiên trong thời tiền sử Việt Nam. Tạp chí Khảo cổ học, (3), 88-97.

Nguyễn, K. S. (2005). Khảo cổ học vùng ven biển Đông Bắc Việt Nam: Tư liệu và vấn đề. Tạp chí Khảo cổ học, (3), 3-20.

Nguyê̂n, K. S. (2009). Di chỉ tiền sử Cái Bèo, đảo Cát Bà. Hà Nội, Việt Nam: NXB. Khoa học Xã hội.

Nguyễn, K. S. (2012). Khảo cổ học hang động Tràng An - những giá trị lịch sử văn hóa nổi bật. Tạp chí Khảo cổ học, (5), 20-32.

Nguyễn, K. S., \& Nguyễn, X. N. (2004). Khảo cổ học tiền - sơ sử Ninh Bình, nét phác thảo. Tạp chí Khảo cổ học, (1), 24-38.

Nguyễn, K. S., \& Phan, T. T. (2019). Không gian sinh tồn của cu dân tiền Óc Eo, Óc Eo. Bài báo được trình bày tại Hội thảo Khoa học Khu Di tích Óc Eo-Ba, Thê-Nền Chùa: Khai quật, Nghiên cứu, Bảo tồn, và Phát huy Giá trị, An Giang, Việt Nam.

Nguyễn, N. (2005). Một số nét về tiến hóa cổ địa lý vịnh Bắc Bộ trong Pleistocene muộn - Holocene và một số vấn đề khảo cổ học liên quan. Trong Viện khảo cổ học, Nhũng phát hiện mói về khảo cổ học năm 2005 (tr. 66-70). Hà Nội, Việt Nam: NXB. Khoa học Xã hội.

Nguyễn, L. C. (2017). Những phát hiện về di cốt người cổ trên đảo và ven bò̀ biển Việt Nam. Bài báo được trình bày tại Hội nghị về Biển đảo Việt Nam Tiềm năng và Triển vọng, Hà Nội, Việt Nam.

Nguyễn, T. C. (1998). Văn hoá Quỳnh Văn. Hà Nội, Việt Nam: NXB. Khoa học Xã hội.

Nguyễn, T. C. (2015). Tiếp cận văn hóa biển tiền sủ Việt Nam. Hà Nội, Việt Nam: NXB. Khoa học Xã hội.

Nguyễn, T. H. (2012). Văn hóa khảo cổ huyện Cần Giờ, Thành phố Hồ Chí Minh. TP. Hồ Chí Minh, Việt Nam: NXB. Tổng hợp TP. Hồ Chí Minh.

Patter, E. (1923). Le fouille d'un kjokkenmodding néolithique a Tam Toa près de Dong Hoi (Annam). Dans Bulletin de l'École Francaise d'Extrême Orient, (XXIII), 409-412.

Phạm, T. N. (2000). Văn hóa Bàu Tró. Hà Nội, Việt Nam: NXB. Khoa học Xã hội. 
Phạm, T. N. (2003). Di tích Đầu Rằm - nhận thức mới về thời đại Kim khí ở vùng ven biển Đông Bắc Việt Nam. Tạp chí Khảo cổ học, (4), 28-46.

Phạm, V. Đ. (1999). Văn hóa Hoa Lộc. Hà Nội, Việt Nam: NXB. Văn hóa Thông tin.

Phan, T. T. (2012). Một số hình ảnh di vật khai quật ở Tràng An (Ninh Bình). Trao đổi riêng.

Schmidt, W. (1906). Die Mon - Khmer - Volker, ein Bindeglied Zwischen Volkern Zentralasiens and Austronesiens. Archiv fur Anthropologie, (5), 59-109.

Trần, Đ. T. (2003). Lịch sủ địa chất vịnh Hạ Long. Quảng Ninh, Việt Nam: Ban Quản lý vịnh Hạ Long.

Trịnh, D. (2007). Vịnh Hạ Long - giá trị tiêu biểu về địa chất, địa mạo. Bài báo được trình bày tại Hội thảo Giá trị đa dạng tiêu biểu Di sản Thiên nhiên Thế giới vịnh Hạ Long, Hà Nội, Việt Nam.

Vũ, Q. H. (1999). Văn hoá Xóm Cồn và vị trí của nó trong thời đại Kim khí ven biển miền Trung (Luận án Phó Tiến sĩ), Viện Khảo cổ học, Hà Nội, Việt Nam.

Vũ, Q. H., \& Trịnh, C. (1986). Di chỉ Bàu Dũ (Quảng Nam - Đà Nẵng) quá trình phát hiện, kết quả nghiên cứu, và nhận xét sơ bộ. Tạp chí Khảo cổ học, (4), 16-39.

William, C. (1978). Aminal, fish remains: Identification and analysis of excavated fish remains. Journal of the Hong Kong Archaeological Society, (3), 185-188. 